\title{
Home truths from abroad
}

\author{
John Launer
}

I recently paid a visit to Brown University in Providence, Rhode Island. My aim was to exchange ideas about postgraduate training with the medical teachers there. Brown is one of America's leading universities, and I saw a great deal that challenged my preconceptions about medicine in the USA, and also made me question some of our working practices in the UK. Most of my time was spent observing my hosts as they carried out their own clinical and educational work. One of the events I observed was a ward round in a high dependency unit. I joined an attending physician, her chief resident, and the intern on the team-the equivalent of consultant, specialist registrar, and foundation year doctor. I watched and listened as they reviewed the patients they had admitted during the previous $24 \mathrm{~h}$.

I was immediately struck by the courtesy that the team members showed for each other. No doubt Brown is an exceptional place, and perhaps this team was especially well matched, but I couldn't help remarking on the conspicuous lack of hierarchy or reserve in their conversation with each other. Setting aside the difference in their ages, it would have been easy to imagine that they were professional equals: a kind of levelling-up of power relations which I believe one still rarely sees in the UK.

Also, for whatever reason, their discussions seemed unhurried. Evidently they had set aside lots of time for case based teaching. At first, I thought they may have created special conditions because they knew I would be present as an observer. However, later on that morning I made an unscheduled visit to an outpatient clinic and found that one senior consultant had been assigned the role of preceptor for the whole session. He was thus available as a teaching resource for the residents to consult, without any clinical duties of his own. This was clearly an ideal arrangement from an educational point of view, and one that I have never encountered elsewhere.

Correspondence to Dr John Launer, London Deanery, London Department of Postgraduate Medical Education, Stewart House, 32 Russell Square, London WC1B 5DN, UK; jlauner@londondeanery.ac.uk

\section{TIME FOR REFLECTION}

Another thing that struck me on the ward round was the consideration shown towards patients. The team held the majority of their discussion at the nursing station, out of sight and out of earshot of the patients themselves. They talked through each case in detail before making a decision about which of them should then go to each patient individually, and what issues they needed to discuss with that person. It was a style of ward round that evidently gave the doctors adequate time for reflection as clinicians, as well as a chance to prepare for an intimate and fully briefed conversation with the patients afterwards. (Contrary to my expectations, I also discovered that a university hospital cannot turn patients away on the basis of having no insurance-although discrimination on financial grounds is obviously a massive problem elsewhere in the US medical system.)

However, I found one thing quite perplexing. The attending physician on the high dependency unit had actually introduced herself as a family physician when we met. She also explained that her juniors were also training in family medicine. Yet I saw and heard little on the ward round that resembled anything I would hear family doctors talk about in the UK. Virtually all the discussion revolved around the highly technical details of clinical care. I was impressed that my US counterparts clearly knew so much more than I did about sophisticated hospital treatment: as a general practitioner (GP) in the UK, I could barely understand some of it since a number of the patients were undergoing complex interventions or therapeutic regimens. On the other hand, I was alarmed that this team might be out of its depth in dealing with such complex cases. I was also concerned that so much of the dialogue seemed highly scientific and biomedical, with little about the family and social circumstances of the patients, or their own attitudes, beliefs or wishes-whereas no GP educator back home would ever talk about a patient for more than a minute without bringing something of that individual's personal story into the conversation.

\section{WORKING TOGETHER CLOSELY}

After thinking about this for a few minutes, I put my concerns to the team in a way that I hoped wouldn't sound too critical. The attending physician's answer gave me a great deal to think about. First, she explained that specialists in family medicine at Brown - and in some other US institutions too-work far more closely with their specialist colleagues than would ever be the case in the UK or indeed in most of Europe. They have admitting rights to hospitals, and continue to care for their own patients on the wards, calling on further specialist help as and when necessary, but continuing to keep overall responsibility for the patients. Thus, they are obliged to keep far more up-to-date with modern inpatient medicine, and to attend more of their medical education alongside their other physician colleagues.

As far as the biomedical bias of the ward round conversation was concerned, she remarked that this was simply because all the doctors knew the patients so well. All the people they were currently seeing on the ward were ones she had looked after as a family physician for several years. Their personal details and family situations were so well known to her and her juniors that it wasn't necessary to allude to them, especially at a time when there were crucial technical decisions to make.

\section{DIVISION IN MEDICAL CARE}

Her explanation set me thinking about the situation in the UK, where the division between primary and secondary care is so much sharper. Many years ago the sociologist Frank Honigsbaum wrote an acute and somewhat damning history of the way that this division first developed. ${ }^{1}$ He explained how hospital specialists and GPs held on to their own financial and professional vested interests when the National Health Service was founded, so that the two kinds of medical practitioner in the UK virtually branched off into different species. He argued that this division had been neither necessary nor desirable, and that other countries had managed to avoid it, or at least to lessen the divide between primary and secondary care physicians in terms of their status and responsibilities.

In the course of my own career-carried out almost entirely since Honigsbaum wrote his book-the division has, if anything, become more accentuated. My impression is that the average hospital consultant in the UK is even less likely than a generation ago to know any members of the local GP community well, 
let alone to work alongside them professionally in any significant way. Many of the structures and institutions that used to cross the divide to some extent, like community hospitals or shared postgraduate lecture courses, have vanished, often leaving the two sides with little knowledge of each other. As a result, hospital referrals from GPs have acquired the status of messages stuffed into bottles, and tossed onto the bureaucratic waves of large, impersonal institutions. The consequences for patients, in terms of shared knowledge and understanding among their professional carers, have been disastrous.

My visit to Brown highlighted a number of things for me, including the value of democratic relationships between teachers and trainees, and of protected time for case based education. But the most important lesson was that there doesn't have to be a yawning and dysfunctional gulf between care in the community and hospital care, even in highly technological societies. We need to train young doctors so that they can see and care for the same patients in hospital beds that they have seen across the desk in the GP surgery-and to have a constant sense that these are the same people, with the same needs, the same identities, and the same entitlement to respect.

Competing interests None.

Provenance and peer review Commissioned; not externally peer reviewed.

Postgrad Med J 2010;86:191-192. doi:10.1136/pgmj.2010.097055

\section{REFERENCE}

1. Honigsbaum F. The division in British medicine. London: Kegan Paul, 1979.

\section{Corrections}

An article published in the February 2010 issue of the journal (Toft, B. The dangers of heparin flushes. Postgrad Med J 2010;86:65-6) should have been labelled as a reprint. It should have contained the note "This is a reprint of a paper that appeared in Quality \& Safety in Health Care, April 2009, volume 18, pages 84-5. Reproduced with kind permission of author and publisher".

Postgrad Med J 2010:86:192. doi:10.1136/qshc.2008.028324corr1

An article published in the February 2010 issue of the journal (Asghari F, Fotouhi A, Jafarian A. Doctors' views of attitudes towards peer medical error. Postgrad Med J 2010;86:123-6) should have been labelled as a reprint. It should have contained the note "This is a reprint of a paper that appeared in Quality \& Safety in Health Care, June 2009, volume 18, pages 209-12. Reproduced with kind permission of author and publisher".

Postgrad Med J 2010:86:192. doi:10.1136/qshc.2008.025015corr1 